\title{
Feedback
}

\section{On social cybernetics}

I am sorry to have to raise the issue of cybernetics again in connection with the comments on "Control bureaucracy and power" (HSM 2(4) (1981) 316-321) appearing on page 245 of the same issue:

“... Humans behave like deer stags, fighting it out according to inherited primeval urge. Brix does not need concept of purpose, choice, compromise, compassion, recognition, public service, leadership, sacrifice, altruism, voluntarism, self-sacrifice,... sense of being useful, groups belonging, love, joy, satisfaction, achievements,... goals, creativity, art, and problem solving."

I am still very worried about the impression this picture might give to HSM readers, for, as far as I am concerned, if these assertions were truthful I would be the last person to waste my and other people's time by presenting such 'ossified' models.

I have found, to my surprise, that the literature of analytical psychotherapists is based on almost the same model of dependence as I have put forward in my papers. Having been guided by a behavioral psychologist, my efforts had not turned toward the rich fields of psychotherapy. I venture to present a few examples:

(1) Fairbain \& Ronald, Psychoanalytic Studies of the Personality, Tavistock, 1952, p. 145.

"What distinguishes mature dependence from infantile dependence is that it is characterised neither by a one sided attitude of incorporation (this is what I call a dominating mode) * nor by an attitude of primary emotional identification (this is 'submission') *. On the contrary it is characterised by a capacity on the part of a differentiated (I underline this) * individual for cooperative relationships with differentiated objects. So far as the appropriate biological object is concerned, the relationship is of course genital; but it is a relationship involving evenly matched giving and taking between two differentiated individuals who are mutually dependent and between whom there is no disparity of dependence (isn't this balanced interdependence?) *. Further the relationship is characterised by an absence of primary identification and an absence of incorporation (one

North-Holland Publishing Company

Human Systems Management 3 (1982) 209-211 being dominance, the other submission)*. At least this is the picture but of course it is never completely realised in practice since there is no one whose libidinal development proceeds without a hitch.

(2) Antony Storr (The Integrity of the Personality, Penguin, 1960) seems to base psychotherapy on the results of the interaction between child and parent. The dependency relationship between them, i.e, the child being dependent on the parent goes against the need to develop the child as an adult, independent in its own right. The neuroses we see today result largely from the ambiguity of this child-parent relationship, none of us (I say this as a parent) * know when to be authoritarian or to be permissive.

I had no idea that the model which I have put forward was actually that in use by psychiatrists, i.e, the neo-Freudians, for many years.

(3) Eric Fromm (The Fear of Freedom and The Sane Society) shows how to be fully developed (self-realisation) the ego cannot be on its own, it has to merge with an appropriate system of other egos but to stand by itself and be differentiated from them. The ego therefore has to form a system with other egos which are differentiated from it, a theme which I have brought out in the cybernetic approach.

(4) It is significant that Jung proposed many years ago that the "psyche is self-regulating". He suggested that dream, fantasies and neuroses are correcting processes working towards preserving an equilibrium, and this theme is quoted by Anthony Storr.

(5) the psychiatrists appear to describe falling in love as a kind of balance between two differentiated human beings. Each lacks what the other one desires, and, it would appear there should be no unbalance of dependence in the relationship.

I have had discussions recently with an

\footnotetext{
* My insertions, V.H. Brix.
} 
educationalist, one who has followed the careers of many children as teacher, and headmistress. She has not drawn my attention to serious inadequacies in the model, but has enriched the model by her own observations.

Rather than scrap the whole thing as 'ossified' (like the economic model with which I have compared it) I think it might be advisable to pursue social cybernetics as a method of presenting a very wide range of concepts to young people in the secondary education stage, before they become directed into various specialities, for the approach does straddle psychology, biology; anthropology, management, psychiatry and economics, and so should be useful in interpreting the complexity of todays problems.
V.H. BRIX

'La Bourdette', Gibel Nailloux, France

\section{Epistemological foundations of a publications policy: its application to HSM - A comment}

Van Gigch's paper does not jibe in any way with my own perception of HSM as a publication aimed at providing a broader understanding of the problems of human systems management.

Prof. van Gigch tries to distinguish between two publication audiences-'scientists /academicians' and 'managers/practitioners'-without defining clearly the exact scope and nature of each audience. Nevertheless, he then proceeds to propound a curious theory of information flow-'Knowledge Type 1' which somehow trickles down into 'Knowledge Type 2'. This amounts, in my opinion, to sheer academic arrogance.

As the makers of development decisions affecting virtually every known field of human activity, all managers and practitioners-particularly the various professions and the CEOs and directors of large corporations (including universities)-are also, through their specialized use of the knowledge generally available to society, the generators of information (new knowledge) which can be garnered, processed and disseminated to other managers and practitioners in the same field or in other related and interacting fields of activity (including the various academic disciplines).

The broader and more detailed the overall view of what is happening everywhere on this planet, the more desirable becomes the outflow of new knowledge (wisdom). The specialists in each field are, of course, primarily concerned with the details of development within their individual areas of expertise, but since every field of activity is affected ultimately (sooner or later, in varying degree) by what happens elsewhere, they should all have access to informational inputs of an integrative nature (interdisciplinary, interprofessional, interindustrial, intersocietal, intercultural, etc.) which call attention to new development possibilities that should be considered in their decision-making routines. Such information must be succinct and free of all professional and academic jargon if it is to be readily comprehended by an increasing variety of specialists.

This is the role I see HSM performing as an intellectual service which seeks to promote a worldwide coordination and development of all human knowledge (wisdom) for the benefit of all mankind.

The hierarchy of publications based inversely on their frequency of issue, with newsmagazines and newspapers at the lowest level, which Prof. van Gigch suggests as an indicator of quality in any evaluation of information and knowledge is likewise rather specious reasoning. HSM's own performance could be enhanced greatly, I believe, if its publication schedule could be speeded up. 
Very much to be desired is HSM's early transformation into an electronic teleconferencing network that will permit widespread instant analysis of human systems management problems and their possible solution in terms of peaceful conflict reso- lution worldwide, as advocated for example by Thomas Saaty (see HSM 3 (4), next issue).

C. Theodore LARSON 